\title{
Poverty in Canada
}

\author{
by Raghubar D. Sharma \\ Don Mills ON: Oxford University Press 2012 \\ ISBN 978-0-19900-322-8 \\ Softcover, $\$ 18.95,176 \mathrm{pp}$.
}

\section{Reviewed by Ravi B.P. Verma}

Canada is one of the G7, the wealthiest countries in the world, where poverty should be non-existent. The book Poverty in Canada by Dr. Raghubar D. Sharma brings to light the stark realities of those within some segments of society who struggle to have life's necessities in the midst of prosperity. The book is the first concise statistical account on inequality in incomes among the Canadian population, and a valuable addition to the literature on the subject. It is based on supporting data sources, relevant materials, analysis, and explaining observations, using several theories of social stratification. This study by Sharma is done on his experiences acquired through research and teaching, as well as working as a social demographer in the provincial public service for 33 years. The major focus is to review selected socio-economic groups of the Canadian population that have been marginalized due to their low income. As such, they lag behind in reaching a better socio-economic life. These groups are: ethnic groups (recent immigrants), the Aboriginal population, the elderly, single mothers, children, and the working poor. Regional income disparity and Canadian poverty levels over global averages are also described. Due to poverty, some in these groups to resort to crime, suffer from mental health problems, drop out of school, and ruin their family life. The analysis provides a good framework to understand poverty in terms of cultural aspects, situational perspectives, stigma of poverty, and social exclusion. This book is indeed an innovative contribution.

It begins with a description of how poverty can be understood as a concept in detail (Chapter 1). It is a much better approach than simply understanding numbers and rates on poverty. According to Sharma, no single one of these perspectives can fully explain why poverty remains so pervasive in Canada (p. 10). What is poverty and how is it measured? Canada has no official definition of poverty. However, it may be defined as the economic status of individuals who lack a certain amount of material possessions or money to meet their daily needs of life. This could be of two types: objective or absolute poverty and subjective or relative poverty. Absolute poverty refers to the deprivation of basic human needs in terms of food, water, sanitation, clothing, shelter, healthcare, and education. In contrast, relative poverty is defined as economic inequality in the location or society in which people live. This book focuses more on aspects of relative poverty. The Appendix contains a critical overview of the various measures of poverty that are commonly used by researchers in federal/provincial governments and other researchers in Canada. These measures are: low-income cut-offs (LICOs), low income measure (LIM), and Market Basket Measure (MBM). The poverty line is determined by households living on 50 percent of the Canadian average family income. Of these measures of poverty, the author has preferred to use data based on Statistics Canada's low-income cut-offs, which are available since 1970 (Catalogue \#75-202, Income in Canada). However, this measure has been associated with a note of caution for users by Dr. Ivan Fellegi (1997), the former Chief Statistician of Canada. He stated that Statistics Canada does not necessarily measure the level of "poverty" in Canada. The data on low-income cut-offs are quite different from measures of poverty. "The lowincome cut-offs identify those who are substantially worse off than the average. Of course, being significantly worse off than the average does not necessarily mean that one is poor." Therefore, the scenarios of poverty of different groups of people in Canada presented in this book should be understood in light of this caution.

In Chapter 2, it is stated that ethnic poverty in Canada is due to social exclusion based on racial and ethnic discrimination (p. 13). Some evidence related to the poverty of recent immigrants/visible minority groups, and Aboriginal groups. is well documented by reviewing studies by other researchers. For example, with refer- 
ence to the study by Basavarajappa and Verma (1988), Sharma suggests that "the higher proportion of newly arrived immigrants below the poverty line in Canada can be explained by the minority group hypothesis" (p. 19). Also cited is the study of Reitz (2005), which shows that "foreign-trained immigrants were better educated than native-born Canadians, yet they had a difficult time in finding work in areas they were trained in, and their incomes were falling further and further behind." This could be due to the fact that some of them are socially excluded due to prejudice, which leads to discrimination. No doubt, both are important components of racism that hinder the full participation of minority groups against which racism is directed. Thus, racism supports social exclusion. It exists in Canada, but is not widespread as a fundamental feature of Canada (Richmond 1988; Satzewich 2011). To eliminate discrimination from the labour market, some statutory protections are implemented by the government since 1970 . However, as Sharma states, “... the poor recent immigrants: they cannot fight discrimination in courts of law because to fight a legal case you need money, and to have money you need a job” (p. 23). It seems that these poor recent immigrants are at the mercy of God.

In contrast to the recent immigrants, ethnic poverty and segregation and discrimination affect more adversely the Aboriginal peoples (North American Indians, Métis, and Inuit) in Canada. First, Sharma reviews their socioeconomic and demographic indicators based on the Canadian census database and other administrative files. As compared to the non-Aboriginal population in Canada, the Aboriginal peoples today still have higher fertility and mortality, but these rates are declining. Also, low income is a reality for the Aboriginal population. In 2005, Aboriginal peoples on average earned two-thirds as much as non-Aboriginal peoples. Notably, average annual incomes for the First Nations peoples $(\$ 19,000)$ and Inuit $(\$ 25,000)$ were much lower than for non-Aboriginal people aged 25 to 54 years $(\$ 33,000)$. Thus, as Sharma points out, “this minority lives in poverty" (p. 27). The causes of poverty among the Aboriginal peoples are due to Canada's colonial history, the impact of dominant values, power, and minority status. He also finds that the discrimination/culture of poverty, situational perspective, stigma of poverty, and social exclusion are relevant to understanding the poverty of Aboriginal peoples in Canada.

Chapter 3 deals with the poverty of elderly people aged 65 years or more who are retired from the labour force, and getting income from their private pensions, investments, and other social benefits from public sources such as OAS, GIS and Spouse Allowance, CPP/CQP, GST/HST Credits and Supplements, etc. Some of them, who receive a good pension and investment income, are economically better off, and pay income taxes, too. However, the majority of the elderly in Canada are solely dependent on government assistance. Sharma's analysis of poverty among the elderly shows that in 2002, there were more than half a million elderly poor, with 77 percent of them unattached and 23 percent living in families (Table 3-1, p. 41). In 2006, according to Statistics Canada, one-third of the elderly in Canada lived alone (p. 38). Also, it has been observed that a growing number of widowed and single elderly would prefer to live on their own rather than living with relatives or in institutions (Myles 2012). Thus, poverty of the elderly is the problem of the unattached elderly; they had higher rates of poverty ( 38.7 per cent) than the non-elderly aged 18-64 (30.9 per cent). However, regardless of gender and family type, Sharma has shown that the poverty rates in Canada have declined over the period 1983-2002 (Table 3-2). For example, poverty rates among the elderly living with families declined considerably, from 13.7 per cent in 1983 to 4.9 per cent in 2002. In contrast, the decline in poverty rates among the unattached elderly was relatively slower, 68.1 to 38.7 per cent. This difference is attributed simply to the fact that the elderly in families benefit from the pooled income of two persons. However, one could also allocate some of these differences in declining poverty rates over time due to changes in the quality of data. The quality of income data are well reported in Statistics Canada Catalogue 75-202-XIE. For example, the data prior to 1993 were drawn from the Survey of Consumer Finances (SCF). Beginning with 1998, the data were taken from the Survey of Labour and Income Dynamics (SLID). For the 1993 to 1997 period, estimates were based on a combined sample from SCF and SLID. Nevertheless, there is no doubt that poverty rates among the elderly in Canada have been declining since the 1980s. And they are expected to be better off in the future, thanks to increasing levels of education, but the low incomes among recent immigrant seniors, Aboriginal elderly, and unattached elderly (particularly women), is a matter of concern. The stigma of poverty and social exclusion are more important and relevant than other concepts - culture of poverty and situational perspective - to appreciate the poverty of seniors in Canada.

Social exclusion is also a relevant factor to be taken into account to comprehend the poverty of women in Canada (Chapter 4). Today, poor women outnumber poor men, and they run a higher risk of poverty than men. This phenomenon has been termed as the feminization of poverty (p. 51). Statistics on women's poverty in Canada are quite 
stark. In 2005, of about 1.8 million poor women, two-thirds lived in families and one-third were unattached (p. 54). Whether poor women lived in families or were unattached, their poverty percentage was higher than that of the poor men, confirming the "feminization of poverty" phenomenon. A large proportion of women in poverty are single mothers who demand daycare services in order to work. According to Statistics Canada (February 24, 2012), "Even today, women in Canada are paid only 65 percent of men's wages, and they do unpaid work, which includes housework, child care, meal preparation, and eldercare" (Veerle 2011: 70). As women are participating in low-paid jobs, they are socially excluded, and they also suffer from exclusion due to discrimination (p. 70). This is particularly true for Aboriginal, immigrant, visible minority, elderly, and disabled women, who are doubly disadvantaged. In this chapter, Sharma presents the real stories of three poor women who have experienced hardships due to their low income. These stories are poignant to appreciate the real life of poor people, rather than a poverty rate analysis based on the low-income cut-off. Also discussed in this chapter are the causes and consequences of poverty among women. Poor women are different from non-poor women, because they lack a man's or partner's earning power. The causes of poverty among women are lodged in many social and economic institutions of society: socialization, marriage, motherhood, marital dissolution, and women's position in the labour market (p. 61). In Table 4-1 (p. 55), a typo error was noticed: the proportion of female-to-male ratio (persons below low-income cut-offs after tax), Canada should be 26.9 per cent in 1990 instead of 29.9 per cent.

In dealing with child poverty in Chapter 5, Sharma mentions that all four concepts (the culture of poverty, the stigma of poverty, the situation perspective, and social exclusion) are relevant to explain child poverty, because it is a complex issue. Although the definition of children is not specified in the book, I assume that the analysis of child poverty is based on children less than 18 years of age. Also, poor children refers to those children who are living in low-income families. Particularly, children living in families headed by female lone parents are at the highest risk of poverty. Vulnerable children are minority children. In 2009, out of 2.3 million poor Canadians, 28 percent were children (p. 73). It is shown that Canada has not been successful in reducing poverty among its children, as it has been among its elderly over the period 1983-2009. Factors explaining the slow progress in reducing child poverty in Canada are thoroughly discussed in this chapter. The prime factor is the low level of social spending by the government to reduce child poverty in Canada, as compared to 26 OECD countries (UNICEF 2005). Canada devoted a little over 5 percent of its national income to social spending, and ranked 19th among 26 OECD countries (p. 85). In addition to the need for more social spending to reduce child poverty, it would be equally useful to publicize the success stories of children brought up in poor families, which could serve as a motivating factor to achieve their goals.

Chapter 6 presents the profiles of working Canadians under 65 years of age by the poverty line. The working poor are those who obtain more than half of their income from employment, the other poor are those who earn less than half of their income from employment, and those with incomes above the poverty line are termed the non-poor (p. 88). In 2001, there were 15.9 million workers (excluding non-full-time students). Of these, the proportion of working poor to other poor was 11 per cent, representing about 1.7 million. However, the proportion of other poor earning less than half of their income from employment was 62 per cent, which is much higher than that for the working poor (38 per cent). Some evidence was quoted by the author, who rejects the myth that "the poor do not work." According to Fleury and Fortin (2006 study), the main reason behind worker poverty is that most of them work part-time, part of the year, and for an unsteady number of hours (p. 89). Four factors important in relation to the working poor are discussed in the book: unemployment, growth in two-earner families, government transfer payments, and major government programs. Policies encouraging employment stability will improve the plight of the working poor (p. 102). Also presented is an analysis of the minimum wage earnings for a worker working 40 hours for 40 weeks in each province and Canada. It is noted that minimum-wage workers in Canada earn between 34 (in Alberta) and 46 (in Nunavut) per cent of the average wage. This was found to be inadequate and an unrealistic cure for the working poor, because "the majority of the working poor work less than year-round, and the self-employed working poor are not included in minimum wage legislation” (p. 101). In sum, situational and social isolation perspectives are important to explain the working poverty paradox.

Chapter 7 describes regional poverty in Canada. Regional differences in poverty rates by province and Canada are presented for the selected years 1982, 1983, 1989, 1993, 1996, 1999, 2002, 2008, and 2009. In 1982, five provinces had higher poverty rates than the national average (12.4 per cent); they were Newfoundland and Labrador (14.9 per 
cent), Nova Scotia (12.5 per cent), New Brunswick (15.0 per cent), Quebec (15.0 per cent), and Manitoba (15.5 per cent). In contrast, by 2009 only two provinces (Ontario at 10.1 per cent and British Columbia at 12.0 per cent) had higher poverty rates than Canada as a whole ( 9.6 per cent). These regional differences are closely associated with local economies. Regional disparities in unemployment, inflation, income, and demographic factors are important determinants of regional poverty (p. 109). For example, Table 7-3 presents data on net migration by province (1991-2006). These data refer to inter-provincial migration rather than net migration, which includes net international migration to a particular province. However, it is observed that "over the 15 years, British Columbia and Alberta have seen big gains of migrants from other provinces, whereas the Atlantic Provinces have lost population to other provinces" (p. 113). The implications of these migration trends for creating employment opportunities are discussed in the text. According to Sharma, disparities in regional poverty could be understood in terms of social exclusion and situational perspectives.

Chapter 8 explores aspects of globalization and poverty. The rising trend of social inequality and economic uncertainty in some developed, developing, and underdeveloped countries is analyzed. Everywhere these problems are arising due to the effects of globalization, which refers to "integration of the economies of nations made possible by advances in communication" (p. 121). Due to advances in information technology, the globalized economy creates either high-skilled high-tech jobs or low-skilled service jobs. As a result, the middle class is shrinking and inequality is increasing (p. 121). Also, data are presented on the distribution of world gross domestic product (GDP 1990; International Geary-khamis dollars), by selected countries and the selected years 1700, 1820, 1950, and 2008 (Table 8-1). These data show the shifting of world wealth over time among the regions. For example, Sharma reported that "Asia's share in the world GDP has more than doubled from 1950 to 2008, whereas the share of the United States and Western Europe has dropped by one-third" (p. 127). Projections of working populations by HSBC over 40 years for different countries are also presented in this chapter, but it is not mentioned whether these projected figures are from the medium, high, or low scenario. Similarly, the projected working population for Canada is included without identifying the scenario of population. According to Statistics Canada (2010), "the working-age population of Canada is projected to decline after 2030. Nevertheless, it would exceed the 2009 level even in 2061" (p. 129). The current poverty situation for Canada is also analyzed. According to the 2008 OECD study, "although poverty rates are high in Canada, absolute poverty is low" (p. 36). Furthermore, projections of Canada's economic indicators by HSBC (2011) for the next 40 years are much more favourable. For example, "Canada's GDP is expected to grow at a healthy average annual rate of about 2.3 percent for the next 40 years" (p. 136). Also, "Canada is likely to continue to refresh its workforce through immigration" (p. 136).

In sum, this book is a useful and interesting piece of work on a hot topic with policy implications; I enjoyed reading it. It is recommended for general readers, students, policymakers, sociologists, economists, and social workers interested in the area of poverty and inequality.

\section{References}

Basavarajappa, K.G., and R.B.P. Verma. 1985. Asian immigrants in Canada: Some findings from 1981 Census. International Migration 23:97-121.

Fellegi, I.P. 1997. On Poverty and Low Income. Available online at www.statcan.gc.ca/ pub/13f0027x/13f0027x1999001-eng.htm

Fleury, D., and M. Fortin. 2006. When Working is Not Enough to Escape Poverty : An Analysis of Canada's Poor. Ottawa: Human Resources and Social Development Canada. Available online.

Myles, J. 2012. Social Composition of the Elderly, in "Aging." The Canadian Encyclopedia. Available online.

Reitz, J. 2005. Tapping Immigrants' Skills: New Directions for Canadian Immigration Policy in the Knowledge Economy. Montreal: Institute for Research on Public Policy.

Richmond, A.H. 1988. Immigration and Ethnic Conflict. London: Macmillan.

Satzewich, V. 2011. Racism in Canada. Don Mills ON: Oxford University Press.

UNICEF (United Nations Children's Fund). 2005. The State of the World's Children 2005. New York: UNICEF.

Veerle, M. 2011. Cooking, Caring and Volunteering: Unpaid Work around the World. Paris: OECD. Available online. 